\title{
Pushing back the frontiers of thoracic surgery
}

\author{
Sudish C. Murthy, MD, PhD, FACS, FCCP
}

\author{
From the Department of Thoracic and Cardiovascular Surgery, Heart and Vascular Institute, Cleveland Clinic, \\ Cleveland, Ohio. \\ Supported by the Cleveland Clinic. \\ Disclosures: Author has nothing to disclose with regard to commercial support. \\ Received for publication March 23, 2018; accepted for publication March 27, 2018; available ahead of print April \\ $19,2018$. \\ Address for reprints: Sudish C. Murthy, MD, PhD, FACS, FCCP, Department of Thoracic and Cardiovascular Sur- \\ gery, Cleveland Clinic, 9500 Euclid Ave/Desk J4-1, Cleveland, OH 44195 (E-mail: murthys1 @ ccf.org). \\ J Thorac Cardiovasc Surg 2018;156:429 \\ $0022-5223 / \$ 36.00$ \\ Copyright (C) 2018 by The American Association for Thoracic Surgery \\ https://doi.org/10.1016/j.jtcvs.2018.03.107
}

Laan and colleagues offer a provocative morsel for us to chew on in this issue of The Journal of Thoracic and Cardiovascular Surgery. ${ }^{1}$ These surgeons have reviewed their fairly contemporary and impressively large experience with surgical management of symptomatic giant paraesophageal hernia, then digest and summarize their data for all of us. They conclude that a procedure that is at least a half century old is still relevant in managing the disease today. Indeed, there is little doubt that they are attempting to push back the frontiers of thoracic surgery with this pronouncement, perhaps to around 1961.

So how can a procedure perfected more than 50 years ago still be relevant? It seemingly took 4 tries to get it right, but the Belsey Mark IV is what these authors compare with laparoscopic Nissen fundoplication for treatment of giant paraesophageal hernia. No, not the Belsey Mark V, VI, VII, or VIII, because those remain uninvented, presumably because the Mark IV was the perfect procedure and was followed by a heretofore unheard of cessation of surgical evolution. But shockingly, somehow and some way, they do in fact show that the old gal holds her own when contrasted with the newer kid on the block, the laparoscopic Nissen fundoplication (with fundectomy).

Before we all jump on the Belsey bandwagon, let me offer a different distillation and some additional food for thought. As I read through the report, it became clear that there is some element of trying to compare an apple with an orange. Not that this can't be done, of course, as you can certainly compare the glycemic index of each, vitamin $\mathrm{C}$ content, cost per unit, number of seeds present, and so on. But can you really determine which is better, the apple or the orange? I doubt it.

Unfortunately, there are enough differences between Belsey and laparoscopic Nissen patients in their study that any meaningful statistical conclusions are weakened, although

\section{Reference} 418-28.

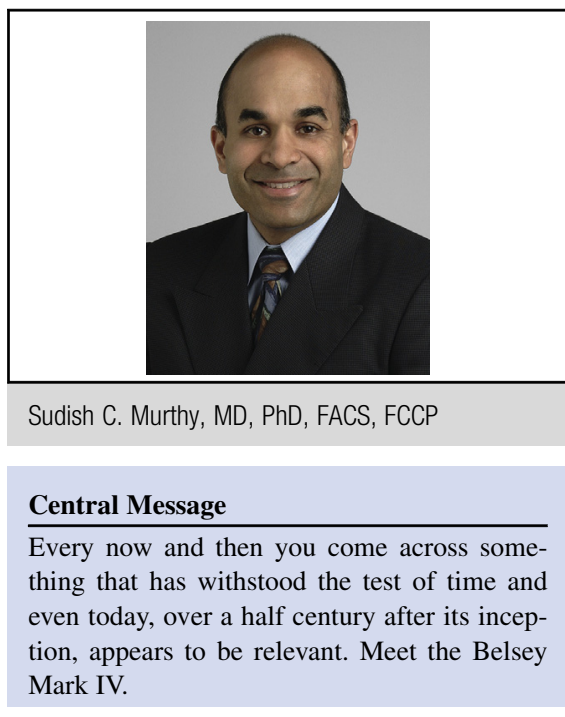

See Article page 418.

the trends and results still need to be respected. For example, the difference in reoperations is greatly confounded by a surprisingly high number of leaks in the Nissen group, which is confounded by a much lower need for functional lengthening in the Belsey group, which is confounded by a lower percentage of super giant hernias $(>75 \%$ of stomach) in the Nissen group, which is confounded by much shorter follow-up in the Belsey group, which is confounded by.... I think you get the point.

But if we just put our analytic spectacles to the side for a minute and read simply for enjoyment, we find that symptomatic control between groups is approximately equivalent at approximately 10 years postoperatively, which is quite remarkable and strongly suggests that vintage doesn't really matter. After all, symptom control is the goal, not radiographic recurrence, not Barrett's progression, and not upfront cost. So take note, especially those reared in the age of less is more and the smaller the better! Perhaps these authors are trying to teach the new dog some old tricks, and the new dog should pay attention.

1. Laan DV, Agzarian J, Harmsen WS, Shen KR, Blackmon SH, Nichols FC III, et al A comparison between Belsey Mark IV and laparoscopic Nissen fundoplication in patients with large paraesophageal hernia. J Thorac Cardiovasc Surg. 2018;156: 